\title{
A EXTRAÇÃO DO MANGANES E SUAS FORMAS DE OCORRENCIA EM ALGUNS SOLOS DO ESTADO DE SÃO PAULO
}

\author{
R. A. Cataxi engenheiro agrônomo, Seçâao de Agrogeologia Instituto Agronómico de \\ Campinas e J. Rowano GaLIr', engenheiro-agrônomo.
}

\section{1. - INTRODUCATO}

O manganês é um elemento exigido em quantidade relativamente pequena pelos vegetais, onde sua concentração não atinge mais do que alguns centésimos por cento de Mn, no material sêco a $110^{\circ} \mathrm{C}$. Entretanto, apesar de ser um "elemento menor" ou "micronutridor", as funções desenvolvidas no organismo vegetal, conferem a êsse elemento o caráter de indispensável na fisiologia das plantas. Dentre as funções que o manganês desempenha nos fenômenos fisiológicos vegetais, a sua influência na síntese da clorofila e nos sistemas de óxido-redução parecem ser as mais importantes.

No solo, ás formas de ocorrência do manganês e a disponibilidade das diversas formas às plantas, apesar de muito estudadas, não estão, ainda, bem exclarecidas. Assim, de acôrdo com os dados apresentados por alguns autores (3) e (1), pode-se concluir que o manganês, além da forma "trocável" c "não trocável", no estado divalente, pode ocorrer na forma de óxidos hidratados em estados de oxidação mais avançados. Existiria, portanto, no solo, manganês na forma de $\mathrm{Mn}^{++}$"trocável" e $\mathrm{Mn}^{++}$"não trocável", óxidos do tipo $\mathrm{MnO}$ e tôdas as formas entre $\left.\mathrm{Mn}_{8}\right)_{4}$ e $\mathrm{MnO}_{2}$. Tôdus as citadas formas estariam em equilíbrio dinâmico (4).

Os microrganismos podem oxidar o manganês divalente para estados de oxidação mais elevados quando o $\mathrm{pH}$ do meio é maior que 5,5 , e a oxidação torna-se rápida em solos bem arejados e com pH entre 6,0 e 7,5. De outro lado, os óxidos de valência elevada podem ser reduzidos, quer pela ação da matéria orgânica, quer por processos biológicos. A matéria orgânica age como redutor, provàvelmente em $\mathrm{pH}$ baixos, ao passo que os processos biológicos de redução têm lugar em qualquer $\mathrm{pH}$, desde que a tensão de oxigênio do meio seja baixa.

Fujimoto e Sherman (3) apresentaram um ciclo do manganês no solo mais simples e que pode ser resumido da seguinte maneira : $\mathrm{O} \mathrm{MnO}$ e $\mathrm{MnO}_{2}$ representam, respectivamente, o estado inicial e final de oxidação do manganês no solo. Essas duas formas são interconversiveis de acôrdo com o potencial de óxido-redução do meio. Outros compostos poderiam se formar pela hidratação do $\mathrm{MnO}$ e $\mathrm{MnO}_{2}$ e posterior associação dos óxidos hidratados, resultando produtos intermediários do tipo $(\mathrm{MnO})_{\mathbf{x}}\left(\mathrm{MnO}_{2}\right)_{\mathbf{y}}\left(\mathrm{H}_{2} \mathrm{O}\right)_{\mathbf{z}}$. 
Estas formas intermediárias, por perda de água, seriam transformadas em $\mathrm{MnO}$ e $\mathrm{MnO}_{2}$, regenerando os compostos primitivos.

Como se observa, as formas de ocorrência de manganês no solo são relativamente complexas, o que determina certas dificuldades na extração do teor "trocável". A maioria dos autores já reconheceu êste fato e Coppenet (2) resumiu muito bem a situação, denominando de "manganês libertado pela técnica de obtenção de bases trocáveis" ao teor extraído com a solução de acetato de amônio, com $\mathrm{pH}=7,00$.

A disponibilidade das diversas formas de manganês (divalente) "trocável" e "não trocável", óxidos superiores hidratados, às culturas não está ainda bem conhecida. Além do manganês solubilizado pela técnica de extração do "trocável", os vegetais podem absorver parte da fração que está na forma de oxidos hidratados superiores.

No Estado de São Paulo já foram estudados vários aspectos do manganês no solo (7) e o presente trabalho constitui mais uma contribuição a êste assunto.

O objetivo principal dêste estudo foi verificar a capacidade de extração do manganês do solo por diversos compostos, tais como: acetato de magnésio, nitrato de magnésio, nitrato de sódio, nitrato de potássio, nitrato de cálcio, ácido nítrico etc., a fim de esclarecer as formas de ocorrência dêsse elemento nos solos do Estado.

\section{2 - MATERIAL ESTUDADO}

As amostras estudadas representam a primeira camada de solo de oito perfis de três dos grandes tipos de solo do Estado de São Paulo, cujas características mais importantes estão reunidas no quadro 1. As amostras P-402a, P-409a e P-465a representam o tipo de solo terra-roxa legítima, procedente de diabase. As amostras P-510a e P-530a representam o tipo de solo massapé-salmourão procedente de gnais. A amostra P-524a está representando o tipo de solo massapé-salmourão, apesar de ser proveniente de anfibolito. As amostras P-534a e P-541a são do solo arenito Bauru, oriundo da rocha sedimentar denominada arenito Bauru.

A $1 .^{a}$ coluna do quadro 1 indica o tipo de solo e o número da amostra. Assim P-402a, representa a primeira camada de solo do perfil registado na Secção de Agrogeologia com o número 402. A 2. ${ }^{\mathrm{a}}, 3 .^{\mathrm{a}} \mathrm{e} 4 .^{\mathrm{a}}$ colunas indicam a textura das amostras em estudo, de acôrdo com a classificação internacional (areia grossa, partículas entre 2 a $0,2 \mathrm{~mm}$; areia fina e limo, partículas entre 0,2 e $0,002 \mathrm{~mm}$; argila, partículas menores que $0,002 \mathrm{~mm}$ ). $\mathrm{Na} 5 .^{a}$ coluna está representado o $\mathrm{pH}$ internacional ( 1 parte em pêso para 2,5 partes em volumes de água destilada). $\mathrm{Na} 6 .^{2}$ e $7 .^{\mathrm{a}}$ colunas aparecem os teores totais em carbono e nitrogênio, respectivamente. Finalmente, na $8 .^{\mathrm{a}}, 9 .^{\mathrm{a}}, 10 .^{\mathrm{a}} \mathrm{e} 11 .^{\mathrm{a}}$ colunas é apresentado o teor "trocável" em potássio, cálcio, magnésio e hidrogênio, respectivamente. 


\section{3 - MARCHA ANALITICA ADOTADA}

a) Marcha analítica usando-se as soluções extratoras de acetato de amônio, com e sem hidroquinona, e acetato de magnésio. Recolheu-se o percolado em copos de $250 \mathrm{ml}$, concentrou-se até $15-20 \mathrm{ml}$ e tratou-se duas vêzes com água-régia $\left(5 \mathrm{ml} \mathrm{HNO}_{3}\right.$ e $\left.15 \mathrm{ml} \mathrm{HCl}\right)$, para eliminar os sais amoniacais e ácido acético. Passou-se para cápsulas e aqueceu-se em banho-maria até secura completa. Depois de secos os conteúdos das cápsulas, os cloretos foram eliminados com $\mathrm{H}_{2} \mathrm{SO}_{4}(1+3) \mathrm{em}$ banho de areia. Deixou-se esfriar, foram adicionados mais ou menos $30 \mathrm{ml}$ de água destilada, 1 $\mathrm{ml}$ de $\mathrm{H}_{2} \mathrm{SO}_{4}(1+3)$, aqueceu-se ligeiramente e filtrou-se. No filtrado, que foi recebido em balões aferidos de $100 \mathrm{ml}$, colocaram-se mais $2 \mathrm{ml}$ de $\mathrm{H}_{2} \mathrm{SO}_{4}(1+3), 2 \mathrm{ml}$ de $\mathrm{HNO}_{3}, 5 \mathrm{ml}$ de $\mathrm{AgN}()_{3}$ a $4 \%$ e, daqui por diante, procedeu-se como foi descrito em 3.2.

Na extração com solução normal de acetato de amônio contendo hidroquinona e com $\mathrm{pH}=7,00$, depois de eliminados os cloretos com $\mathrm{H}_{2} \mathrm{SO}_{4}$ $(1+3)$, os derivados da hidroquinona, resistentes à água-régia, foram eliminados em forno elétrico à temperatura de $550-600^{\circ} \mathrm{C}$. Depois, a marcha analítica prosseguiu conforme foi descrita. Na extração com a solução de acetato de magnésio, os cloretos foram eliminados com $\mathrm{H}_{2} \mathrm{SO}_{4}(1+1)$ em balões de Kjeldahl.

b) Marcha analítica usando-se as soluções extratoras de nitrato de sódio, nitrato de potássio, nitrato de magnésio e nitrato de cálcio. Pipetaram-se $50 \mathrm{ml}$ do percolado, que foram transferidos para um balão aferido de $100 \mathrm{ml}$ e adicionaram-se $3 \mathrm{ml}$ de $\mathrm{H}_{2} \mathrm{SO}_{4}(1+3), 2 \mathrm{ml}$ de $\mathrm{HNO}_{3}$, $5 \mathrm{ml}$ de $\mathrm{AgNO}_{3}$ a $4 \%$ e procedeu-se, daí por diante, como foi descrito em 3.2. No caso particular do nitrato de cálcio foi necessária uma filtração a mais para remover o sulfato de cálcio, formado pela ação do ácido sulfúrico. Aliás, a filtração foi uma operação freqüentemente usada para eliminar o $\mathrm{AgCl}$ formado pela reação entre o $\mathrm{Ag}^{+}$e o $\mathrm{Cl}^{-}$, que ocorria como impureza nas substâncias empregadas como agentes extratores.

c) Marcha analítica usando-se as soluções extratoras de ácido nítrico 0,01, 0,05 e 0,2 normal e $\mathrm{H}_{2} \mathrm{SO}_{4}(1+1)$ com $\mathrm{HNO}_{3}$. Retirou-se uma alíquota de $50 \mathrm{ml}$, transferiu-se para balão aferido de $100 \mathrm{ml}$, adicionaram-se $3 \mathrm{ml}$ de $\mathrm{H}_{2} \mathrm{SO}_{4}(1+3)$ (não foi necessário juntar êste último ácido à solução obtida pelo ataque do solo com a solução de $\mathrm{H}_{2} \mathrm{SO}_{4}$ e $\mathrm{HNO}_{3}$ ), 3-5 ml de solução de $\mathrm{H}_{3} \mathrm{PO}_{4}(\mathrm{~d}=1,689), 2 \mathrm{ml}$ de $\mathrm{HNO}_{3}, 5 \mathrm{ml}$ de $\mathrm{AgNO}_{3}$ a $4 \%$ e procedeu-se daí por diante conforme foi descrito no capítulo 3.2 .

\section{4 - RESUITADOS OBTIDOS}

No quadro 2 estão representados os tipos de solo, o número das amostras e os resultados obtidos $\mathrm{cm}$ equivalente miligrama (c. $\mathrm{mg}$ ) de manganês por $100 \mathrm{~g}$ de "terra fina", com as diferentes soluções extratoras. Em tôdas as amostras e com tôdas as soluções foram executadas duas extrações sucessivas de $100 \mathrm{ml}$ cada uma, com exceção dos casos que serão apontados. Assim, na $3 .^{a}$ coluna do quadro 2 , aparecem os dados obtidos com 


\begin{tabular}{|c|c|c|c|c|c|}
\hline 总 & & 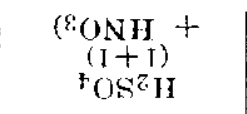 & 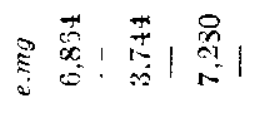 & 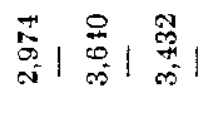 & 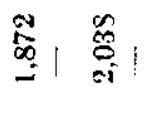 \\
\hline 寻 & & $\begin{array}{l}N z^{i} 0 \\
80 N H I\end{array}$ & 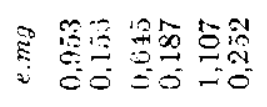 & 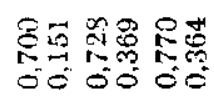 & 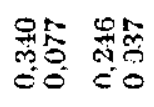 \\
\hline$\stackrel{\mathscr{S}_{2}}{\stackrel{\mathrm{g}}{ \pm 灬}}$ & & $\begin{array}{l}N s 0^{\prime} 0 \\
\varepsilon_{O N H}\end{array}$ & 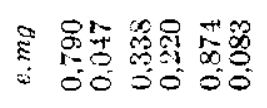 & 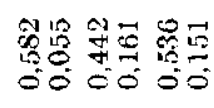 & 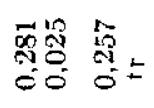 \\
\hline & & $\begin{array}{l}\mathrm{N} I 0^{\circ} 0 \\
\varepsilon_{\text {ONII }}\end{array}$ & 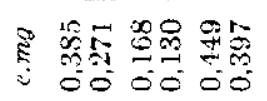 & 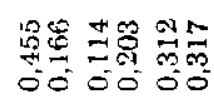 & 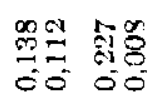 \\
\hline 第 & n & 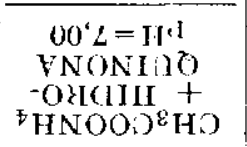 & 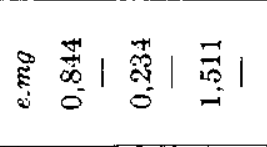 & 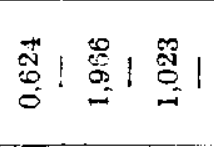 & 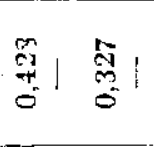 \\
\hline$\stackrel{\substack{0 \\
0}}{0}$ & $\stackrel{m}{0}$ & $\begin{array}{l}00^{\prime} L=I I^{I} \\
I / N \\
\sigma\left(\varepsilon_{O N}\right) n o\end{array}$ & 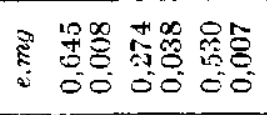 & 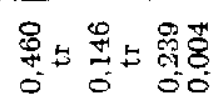 & $\underset{0}{\stackrel{2}{E}}=\frac{5}{0}=$ \\
\hline$\underset{\square}{0}$ & is & 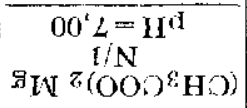 & 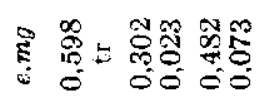 & 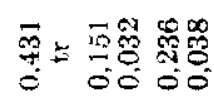 & 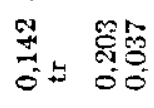 \\
\hline 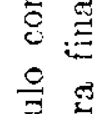 & $\begin{array}{l}n \\
8 \\
15\end{array}$ & $\begin{array}{l}91 ' g=H^{\prime l} \\
\sigma / N \\
z\left(\varepsilon_{O N}\right)^{g} I N\end{array}$ & 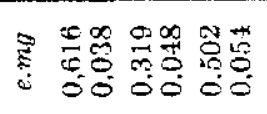 & 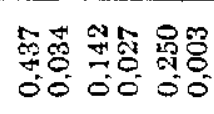 & 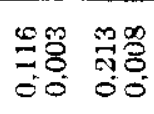 \\
\hline 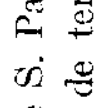 & $\frac{7}{0}$ & 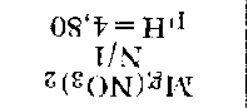 & 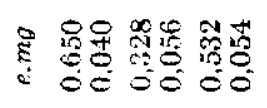 & 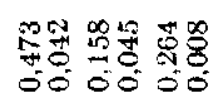 & 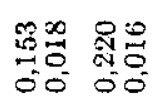 \\
\hline 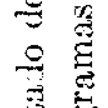 & & $\begin{array}{c}c g^{\prime} g=\mathrm{Hr}^{d} \\
\sigma / N{ }^{2} \mathrm{ONY}\end{array}$ & 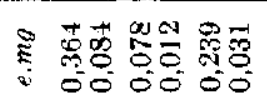 & 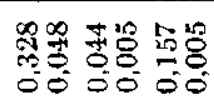 & 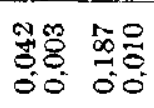 \\
\hline$\stackrel{0}{\circ}$ & & $\begin{array}{l}\mathrm{cg} g=\mathrm{H}^{\mathrm{d}} \\
\mathrm{I} \mathrm{N}^{8} \mathrm{ONH}\end{array}$ & 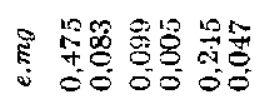 & 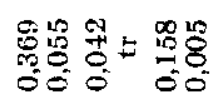 & 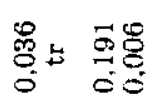 \\
\hline 0 & & 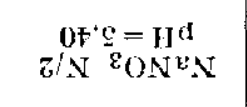 & 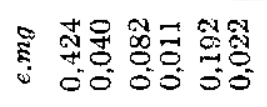 & 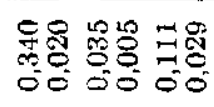 & 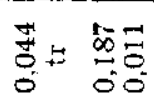 \\
\hline$\overbrace{0}^{+} \frac{}{5}$ & & 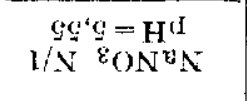 & 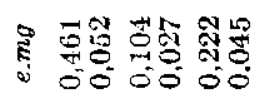 & 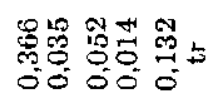 & 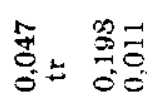 \\
\hline 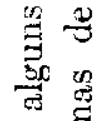 & & $\begin{array}{c}00^{\prime} L=H^{d} \\
V / N \\
{ }_{\text {HINOON }}{ }^{2} 1 \mathrm{IO}\end{array}$ & 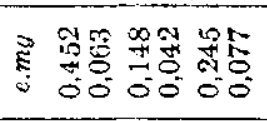 & 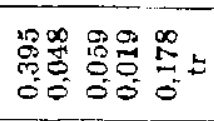 & $\begin{array}{l}90 \\
900 \\
00 \\
00 \\
00\end{array}$ \\
\hline 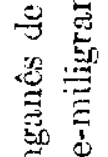 & & 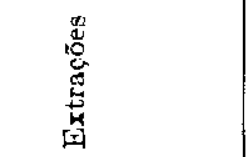 & 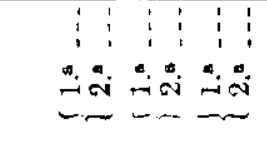 & 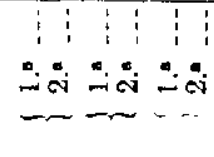 & 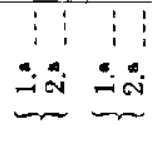 \\
\hline $\begin{array}{l}\stackrel{g}{\Xi} \\
\stackrel{\Xi}{\Xi}\end{array}$ & & 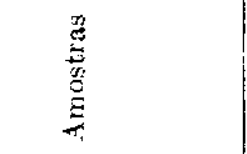 & 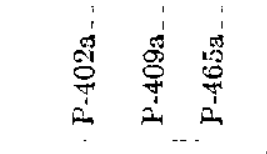 & 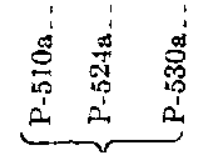 & 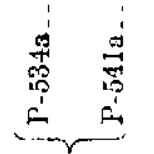 \\
\hline 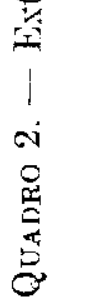 & & 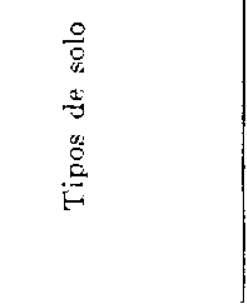 & 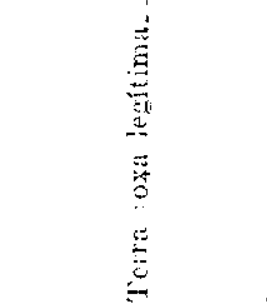 & 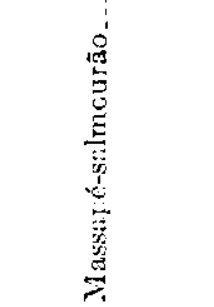 & 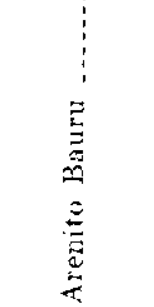 \\
\hline
\end{tabular}


a 1.a e 2." extrações, promovidas pelos diversos extratores. Com a solução normal de acetato de amônio contendo $0,4 \%$ de hidroquinona e $\mathrm{pH}=7,00$ fêz-se uma única extração. Também com a última solução extratora, $\mathrm{H}_{2} \mathrm{SO}_{4}$, $(1+1)$ e $\mathrm{HNO}_{3}$, foi executada apenas uma extração, porque, conforme foi dito em 3.1, o ataque enérgico em balão de Kjeldahl teve como objetivo conhecer o teor em manganês no estado de reserva, ou pelo menos num estado menos solúvel.

No quadro 2, constam ainda o $\mathrm{pH}$ das soluções extratoras formadas de sais de amônio, sódio, potássio, magnésio e cálcio. Essas soluções, cujos pH não foram acertados para 7,00, apresentaram uma concentração em hidrogênio total tão baixa que seu efeito, comparado ao do cátion metálico, torna-se desprezível ( $\left.{ }^{1}\right)$.

Examinando os dados obtidos, vê-se que os primeiros $100 \mathrm{ml}$ das soluçz̃es normais dos sais de sódio e potássio extraíram, de um modo geral, um pouco menos de manganês que a solução de acetato de amônio. No caso dos ions divalentes os dados obtidos foram diferentes. Os primeiros $100 \mathrm{ml}$ das soluções normais dos sais de magnésio e cálcio extraíram mais manganês que a solução de acetato de amônio, em tôdas as amostras. E interessante observar os dados obtidos para os solos do Estado de São Paulo, que indicam a maior eficácia dos fons divalentes, magnésio e cálcio, em relação aos monovalentes, amônio, sódio e potássio, fato êste já constatado também por outros autores (4).

Os primeiros $100 \mathrm{ml}$ das soluçóes meio normais dos sais de sódio e potássio extraíram menos manganês que a solução normal de acetato de amônio, enquanto que a solução meio normal de nitrato de magnésio extraiu mais que a solução referência. Por sua vez, os primeiros $100 \mathrm{ml}$ da solução de nitrato de sódio meio normal forneceram o resultado mais baixo, porquanto com a amostra P-524a extraíram apenas 0,035 equivalente miligrama de $\mathrm{Mn}$ por $100 \mathrm{~g}$ de terra, que correspondem a 9,6 ppm de $\mathrm{Mn}$. Quanto à segunda extração (segunda porção de $100 \mathrm{ml}$ ), quase em todos os casos em que foi usada, houve extração de manganês em maior ou menor quantidade, conforme a natureza da solução.

Os dados obtidos com a solução normal de acetato de amônio contendo $0,4 \%$ de hidroquinona e com $\mathrm{pH}=7,00$, foram mais elevados que os obtidos com qualquer uma das soluções extratoras anteriores (sais de amônio, sódio, potássio, magnésio e cálcio), em tôdas as amostras. Constituiu exceção a amostra $\mathrm{P}-409 \mathrm{a}$, que com os sais magnésio e cálcio permitiu uma extração de manganês maior que a obtida com a solução de acetato de amônio normal contendo $0,4 \%$ de hidroquinona e com $\mathrm{pH}=7,00$. Esta extração evidencia a existência de quantidade relativamente grande de 6xidos hidratados superiores de manganês nas amostras estudadas. Talvez, com solução de outras concentrações de hidroquinona, a quantidade de manganês extraída fôsse diferente.

(1) Assim, $50 \mathrm{ml}$ das soluçōes normais de nitrato de potássio, nitrato de sódio e nitrato de magnésio, tratados com 1 gôta de soluçăo de $\mathrm{NaOH} 0,1 \mathrm{~N}$ tiveram seus $\mathrm{pH}$ transformados de $5,65,5,55$ e 4,80 respectivamente, para $9,50,10,65$ e 7,35 . 


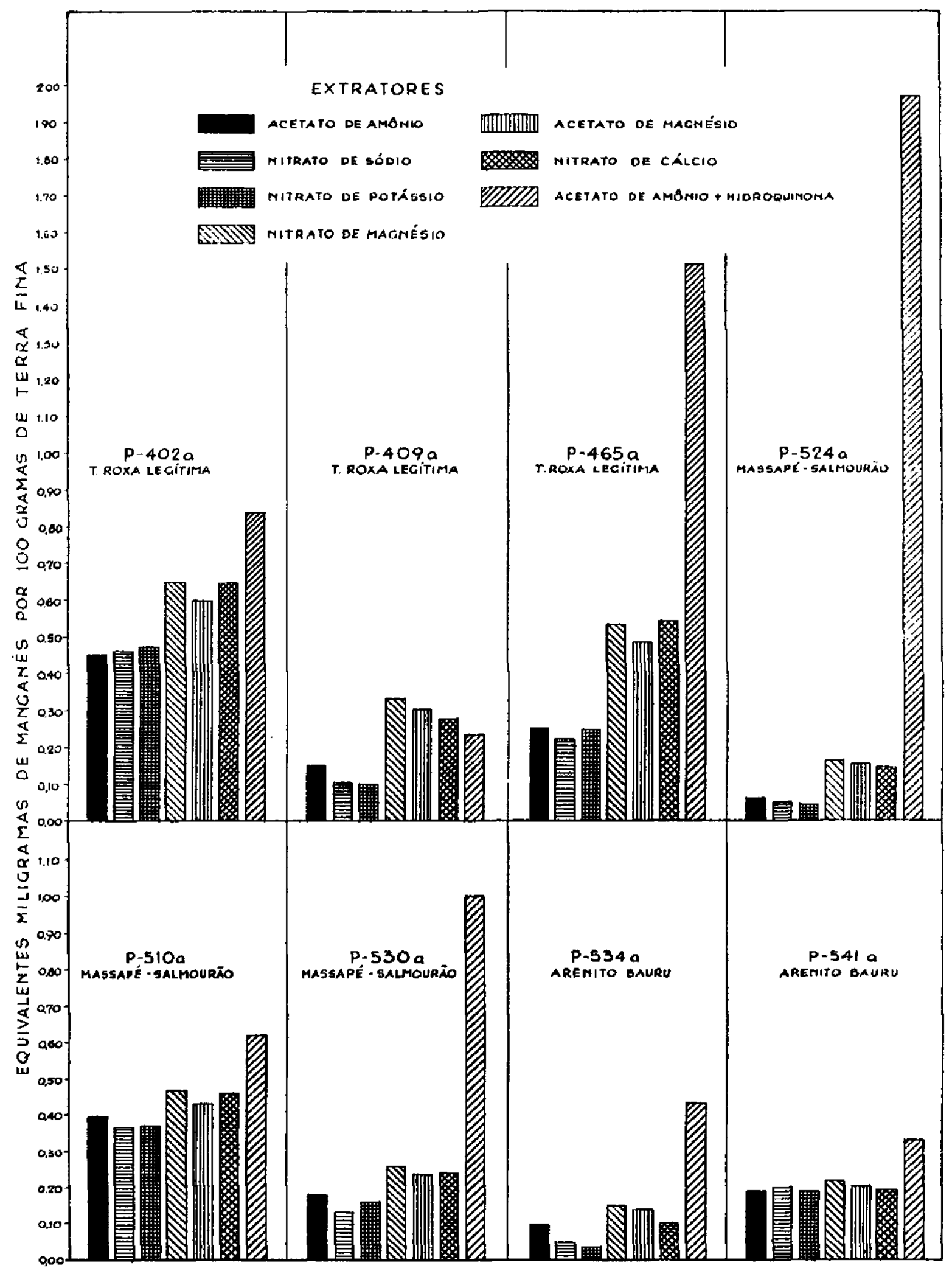

Figura 1.-Teores de manganês dos solos tẹrra roxa legítima, massapé-salmourão e arenito Bauru extraídos por solução normal de acetato de amônio, nitrato de sódio, nitrato de potássio, nitrato de magnésio, acetato de magnésio, nitrato de cáleio e acetato de amônio com $0,4 \%$ de hidroquinona. . 
Um exame comparativo e relativamente rápido da capacidade de extração das soluções normais de sais de amônio, sódio, potássio, magnéxio c rálcio, pode ser feito através da figura 1.

()s dados do quadro 2 discutidos e resumidos pela fig. 1, esclarecem que as amostras de solo estudadas, além de manganês divalente na forma "trocável", apresentam êsse clemento com valências maiores que 2, e, provàvelmente, na forma de óxidos hidratados. (Jutro ponto que deve ser observado é que a capacidade de certos íns (magnésio e rálcio) de extrair maisis manganês que outros (amônio, potássio e sódio), pode estar relarionadi rom o valor do raio iônico hidratado daqueles íns.

No cuadro 2, sâo também apresentados os dados relativos às extra(ços promovidas pelas soluçöes $0,01,0,05$ e 0,2 normal de IINO $)_{3}$. (Os primeiros $100 \mathrm{ml}$ da solução de $\mathrm{HNO}_{3} 0,01$ normal extraíram sempre mais manganês que os primeiros $100 \mathrm{ml}$ da solução normal de acetato do amônio com $\mathrm{pH}=7,00$, com exceção da amostra P-402a. A regunda extração (segundo volume de $100 \mathrm{ml}$ ) com a solução de $\mathrm{HN}()_{3}, 0,01$ normal, forneceu valores maiores que os obtidos pela segunda extração das soluçốes de satis de amônio (sem hidroquinona), sódio, potássio, cálcio e magnésio, com exceção da amostra P-54la. As soluções 0,05 e 0,2 normal de ácido nítrico extraíram quantidades apreciáveis de manganês e sempre maiores que as demais soluçôes, com exceção da solução de acetato de amônio contend"s $0,4 \%$ de hidroquinona e com pH $=7,00$, a qual, na maioria dos casos, extraiu mais.

De um modo geral, as soluçoes de ácido nítrico usadas devem ter extraído, além do manganês "trocável", outras formas, e em sua maior parte provenientes dos óxidos hidratados superiores. Aliás, a existên ia destas formas do manganês já foi indicada pela extraçâo com a solução normal de acetato de amônio, contendo $0,4 \%$ de hidroquinona e com $\mathrm{pH}=\boldsymbol{7}, 00$.

Finalmente, devem ser examinados os dados obtidos com o ataque das amostras com solução de $\mathrm{H}_{2} \mathrm{SO}_{4}(1+1)$ e IINO ${ }_{3}$. Como é evidente, os resultados obtidos foram mais elevados que todos os demais. As amostras de terra roxa apresentaram os valores mais elevados, vindo em seguida as amostras do solo tipo massapé-salmourão e, finalmente, as do arenito Bauru. Estes dados, isto é, o teor extraído pelo $\mathrm{H}_{2} \mathrm{SO}_{4}(1+1)$ e $\mathrm{HNO}_{3}$, evidenciam que as amostras estudadas são relativamente ricas em manganês em reserva.

\section{5 - CONCLUSOES}

a) () manganês ocorreu na forma divalente "trocável" e "não trocável", na forma de óxidos hidratados superiores, entre $\mathrm{MnO}_{\mathrm{m}} \mathrm{H}_{2} \mathrm{O}$ e $\mathrm{MnO}_{2 . n} \mathrm{H}_{2} \mathrm{O}$, e, talvez, em outras formas, em amostras representativas dos tipos de solo: terra-roxa legítima, massapé-salmourão e arenito Bauru.

b) Fm virtude da complexidade de formas de ocorrência, a capacidade de extração dêsse elemento, pelas diferentes soluções extratoras, revelou certa variação. As soluções dos sais de magnésio e cálcio foram mais eficientes que as dos sais de potássio, sódio e amônio na extração do manganês. A 
solução normal de acetato de amônio, contendo $0,4 \%$ de hidroquinona e com $\mathrm{pH}=7,00$, extraiu mais manganês que as soluções anteriores, indicando a existência dêsse elemento no solo, na forma de óxidos superiores. O mesmo fato foi indicado pelas extrações, relativamente elevadas, obtidas pelas soluçôes de ácido nítrico.

c) Não se pode usar a denominação teor "trocável" para o manganês, com a mesma significação que é empregado para os outros cátions. Admitindo-se como referência os dados obtidos pela técnica recomendada para a extração do teor "trocável", isto é, mediante o emprêgo de uma solução normal de acetato de amônio $\mathrm{com} \mathrm{pH}=7,00$, as soluçôes que forneceram resultados mais próximos foram as soluções normais de nitrato de sódio e nitrato de potássio. Em virtude de a marcha analítica de determinação do manganês ser mais simples com o uso de soluções de nitratos, em lugar do acetato de amônio, e, ainda, como a presença do nitrato de sódio não interfere na determinação de outros elementos, como cálcio, magnésio e potássio, o seu uso na extração do manganês torna-se recomendado.

d) As amostras estudadas, representando os solos tipo terra roxa legítima, massapé-salmourão e arenito Bauru, encerram uma quantidade de manganês que deve satisfazer às exigências da maioria das plantas cultivadas do Fstado de São Paulo. Esta conclusão está baseada nos resultados obtidos com as soluções de sais de amônio, sódio, potássio e magnésio. 0 resultado mais baixo, foi o obtido com a solução de $\mathrm{NaNO}_{3}$ meio normal na amostra P-524a, que forneceu 0,035 equivalente miligrama de manganês ou 9,6 ppm de $\mathrm{Mn}$, valor êste acima do admitido como satisfatório, para a maioria das culturas.

\section{RESUMO}

O presente trabalho estuda a capacidade de extração do manganês do solo, por diversas soluções, a fim de esclarecer as formas de ocorrência daquele elemento nos solos do Estado de São Paulo.

Os solos estudados foram representados por três amostras de terra roxa legítima (solo oriundo de diabase), três amostras de solo massapé-salmourão (solo proveniente de gnais, xistos, granitos, etc.) e duas amostras de solo arenito Bauru (solo derivado da rocha sedimentar denominada arenito Bauru). Para extrair o manganês foram usadas as soluções : solução normal de acetato de amônio com $\mathrm{pH}=7,00$; solução normal e meio normal de nitrato de potássio ; solução normal e meio normal de nitrato de sódio; solução normal de acetato de magnésio; solução normal de nitrato de cálcio ; solução normal de acetato de amônio, contendo $0,4 \%$ de hidroquinona e com $\mathrm{pH}=7,00$; soluções de ácido nítrico $0,01,0,05 \mathrm{e}$ 0,2 normal. As extrações foram executadas por percolação usando 100 a $200 \mathrm{ml}$ das mesmas para $10 \mathrm{~g}$ de terra. Foi, também, executada uma extração enérgica, usando-se $\mathrm{H}_{2} \mathrm{SO}_{4}(1+1)$ e $\mathrm{HNO}_{3}$ para conhecer o teor em manganês no estado de reserva.

Os resultados obtidos mostraram que as soluções dos sais de magnésio e cálcio foram mais eficientes que as de acetato de amônio (sem hidroqui- 
nona), de nitrato de sódio e de nitrato de potássio, na extração do manganês. As soluções normais de nitrato de sódio e nitrato de potássio forneceram os resultados mais próximos dos obtidos com a solução normal de acetato de amônio com pH=7,00. $\Lambda$ solução de acetato de amônio contendo $0,4 \%$ de hidroquinona e com $\mathrm{pH}=7,00$ extraiu uma quantidade elevada de manganês, acontecendo o mesmo com as soluções $0,01,0,05$ e 0,2 normal de ácido nítrico.

Os dados obtidos esclarecem que o manganês, além da forma "trocável", ocorre, nas amostras estudadas, na forma de óxidos hidratados, desde $\mathrm{MnO}_{\mathrm{m}_{\mathrm{m}}} \mathrm{I}_{2} \mathrm{O}$ até $\mathrm{MnO}_{2 \cdot{ }_{1}} \mathrm{H}_{2} \mathrm{O}$ e, provàvelmente, em outras formas. Em virtude da relativa complexidade das formas de ocorrência do manganês no solo, a extração do teor "trocável" exclusivo tornou-se difícil. Entretanto, admitindo-se como "trocável" o teor extraído pela solução normal de acetato de amônio com $\mathrm{pH}=7,00$, a solução que mais satisfez, sob os pontos de vista de capacidade de extração e de facilidade de marcha analítica, foi a de nitrato de sódio normal.

O teor de manganês extraído por qualquer das soluções dos sais de amônio, sódio, potássio, cálcio e magnésio das amostras estudadas, mostrou que a quantidade daquele elemento existente nos solos em questão é suficiente para satisfazer às exigências da maioria das plantas cultivadas.

\section{S U M M A R Y}

This paper reports a study concerning the extraction of manganese from several soil types of the State of S. Paulo with different solutions. The soils studied were: 3 samples of a soil type originated from gneiss, granites, shales etc.; 3 samples of a soil type derived from basalts, and 2 samples of a soil type whose original material came from a sandstone.

Manganese was extracted by percolating $10 \mathrm{~g}$ of soil with 100 or $200 \mathrm{ml}$ of the following solutions: normal solution of ammonium acetate, $\mathrm{pH}=7.00$; normal and one half normal solution of potassium nitrate ; normal and one half normal solution of sodium nitrate; normal solution of magnesium acetate; normal solution of calcium nitrate ; normal solution. of ammonium acetate with $0.4 \%$ of hydroquinone, $\mathrm{pH}=7.00 ; 0.01$, 0.05 and 0.2 normal solutions of nitre acid.

Also, a less soluble form of maganese was extracted by treating $1 \mathrm{~g}$ of soil with $\mathrm{H}_{2} \mathrm{SO}_{4}$ and $\mathrm{HNO}_{3}$.

Magnesium and calcium ions were more effective than sodium potassium and ammonium in extracting soil manganese.

Tormal sodium nitrate and potassium nitrate solutions extracted a little less manganese than normal ammonium acetate solution, $\mathrm{pH}=7.00$.

The neutral solution of ammonium acetate plus $0.4 \%$ of hydroquinone, and the $0.01,0.05$ and 0.2 normal solutions of nitric acid extracted large amounts of manganese showing that manganese occurs in several forms in the studied soils. From all indications it is admited that manganese occurs as divalent, tetravalent and probably, in other stages between those valences.

In spite of the fact that it was difficult to determine the exchangeable manganese, it is assumed that the normal sodium nitrate solution was one of the best for extracting that content and for analytical purposes.

From all the data there are indirations that the soils studied are quite well supplied with manganese. 


\section{LITERATURA CITADA}

1. Catani, R. A. e A. Kiipper. As formas "trocável" e "fixa" dos cátions $\mathbf{K}^{+}$, (at+ e $\mathrm{Mg}^{++}$nos solos do Fstado de S. Paulo. Bragantia 9:185-192. 1949.

2. Coppenet, M. Fitude du manganèse dans le sol. Annales Agronomiquess. pág. 666. Ministère de l'Agriculture. Dunod, Paris. 1951.

3. Fujimoto, C. K. e D. Sherman. Behavior of manganese in the soil and the manganese rycle. Soil Sci. 66: 131-145. 1948.

4. Leeper, 6. W. The form and reactions of manganese in the soit. Soil Sci. 63: $79-9.4 .1947$.

5. Leeper, (;. W. e R. J. Swaby. The oxidation of manganese compounds by microorganims in the woil. Soil sci. 49: 163-169. 1940.

6. Paiva Neto, J. E. de, R. A. Catani, N. s. Queiroz a A. Küpper. Contribuig̣ão ac) estudo dos métodos analíticos e de extraçāo para a caracterização químiea dos solos do Estado de s. Paulo. An. da 1." Keunião Bras. de Ciência do Solo, pág. $79-108.1950$.

7. Paiva Nelo, J. F. de. O manganês es onlos do Fistado de s. Paulo. Rev. Agrirultura 16: $515-583.1941$.

8. Peech, M. Em Diagnontic techniques for soils and crops, pág. 15-17. Publ. by The Aneriuan Potash Institute, Washington 6, D. C. 1948.

9. Weber, H. Uber die massanalytische und kolorimetrische Bestinmung des Mangans. Zeit. anal. Chem. 43: 643-65t. 1904. 